\title{
Chinese High School Students Intentions to Study in Canada Based on Push-pull Theory
}

\author{
Zhuoxi Sun ${ }^{1, *}$ Guifang Zhang ${ }^{2,3, *}$ \\ ${ }^{1}$ Gordon S. Lang School of Business and Economics, University of Guelph, Guelph, Ontario, Canada, N1G 2W1 \\ ${ }^{2}$ New Renaissance Academy, Vaughan, Ontario, Canada, L6A $1 S 2$ \\ ${ }^{3}$ Kunming University of Science and Technology,Kunming, Yunnan, China, 650033 \\ *Corresponding author. Email: guifang.zhang@nracademy.ca; ashley.sun.cn@gmail.com
}

\begin{abstract}
This research is based on the theory of the comprehensive effect of internal and external factors derived from the push-pull theory of population mobility, and uses the group of Chinese high school students who will study in Canada as subjects. Questionnaire surveys and interviews have conducted empirical research on the influencing factors of Chinese high school students' willingness to study abroad, and explored the influence of "push-pull theory" factors on Chinese high school students' motivation to study in Canada. The results of the study show that different cultural experiences, new knowledge and skills, different educational methods, and employment in Canada are the main "pull" factors for Chinese high school students to study abroad; China's loose policy of studying abroad, the imbalance of supply and demand in higher education, and quality education institutions insufficiency and other aspects are the main "driving" factors for Chinese high school students to study abroad.
\end{abstract}

Keywords: Push-pull theory, study abroad in Canada, Chinese high school students, students intentions

\section{INTRODUCTION}

Under the combined influence of the continuous development of China's economy, the deepening of opening to the outside world, and the opening of the study abroad policy to China's study abroad policy, more and more students choose to study abroad[1]. According to the latest statistics from Chinese Ministry of Education[3], the total number of Chinese students studying abroad in 2016 was 544,500 , an increase of 20,800 from the 523,700 in 2015 , an increase of $3.97 \%$. As of the end of 2016, the cumulative number of Chinese students studying abroad has reached 4.586 million, with an average annual growth rate of $19.06 \%$, of which 1.3652 million are studying and researching at different stages abroad; and 3.241 million have completed their studies[2]. According to the data of study permit holders published by the Canadian Immigration Department [3], the growth rate of the total number of Chinese students studying in Canada during the 10 years from 2008 to 2017 was as high as $226 \%$. In 2017 alone, there were about 141,000 Chinese students studying in Canada, accounting for $28.4 \%$ of all international students in Canada. This means that nearly 3 out of 10 international students in Canada are Chinese students. So what are the main wishes of Chinese students to choose to study abroad in Canada? In recent years, there has been an endless stream of relevant literature in the field of research on the cause of cross-border higher education. Some scholars have launched a long-term focus on the theme of the international mobility of students. In recent years, push-pull factor theory has become a widely accepted analytical framework for explaining the reasons for international student mobility[4]. Due to socio-economic and political reasons, from the end of the last century to the beginning of this century, China has relatively little research on the practice of students' international mobility and related theories. Research on the choice of Chinese students for cross-border higher education is at an initial stage of development[5]. This article takes Chinese high school students who are going to study in Canada as the research object, uses a combination of quantitative and qualitative methods, studies the influence of push-pull theory factors on high school students' motivation to study abroad, and explores the influence of different cultural experience, new knowledge and new skills, different education methods and employment methods on the "pull" factors of high school students' studying abroad.

\section{RESEARCH THEORIES AND METHODS}

\subsection{Research Theory}

Figure 1 is a theoretical model of the impact of push-pull theory on Chinese high school students' willingness to study in Canada. This model is based on the concept of Herberle's push-pull theory, assuming that studying abroad is caused by a series of "forces", one part is thrust and the other part is pulling[5]. Thrust refers to the fact that there are certain factors in China's supply and demand that are not conducive to students' learning knowledge, and generate a variety of repulsive forces that force students to leave China for Canada, including the 
imbalance between supply and demand in universities, government policy factors, economic factors, students' personal wishes and other special factors. Rally refers to the attractiveness of moving to Canada, including Canadian study abroad policies and high-quality educational resources[1]. Other reasons for "push and pull" may be because the conditions of the move-in place are superior to those of the move-out place, or because the move-in place exhibits more opportunities to make a living and develop.

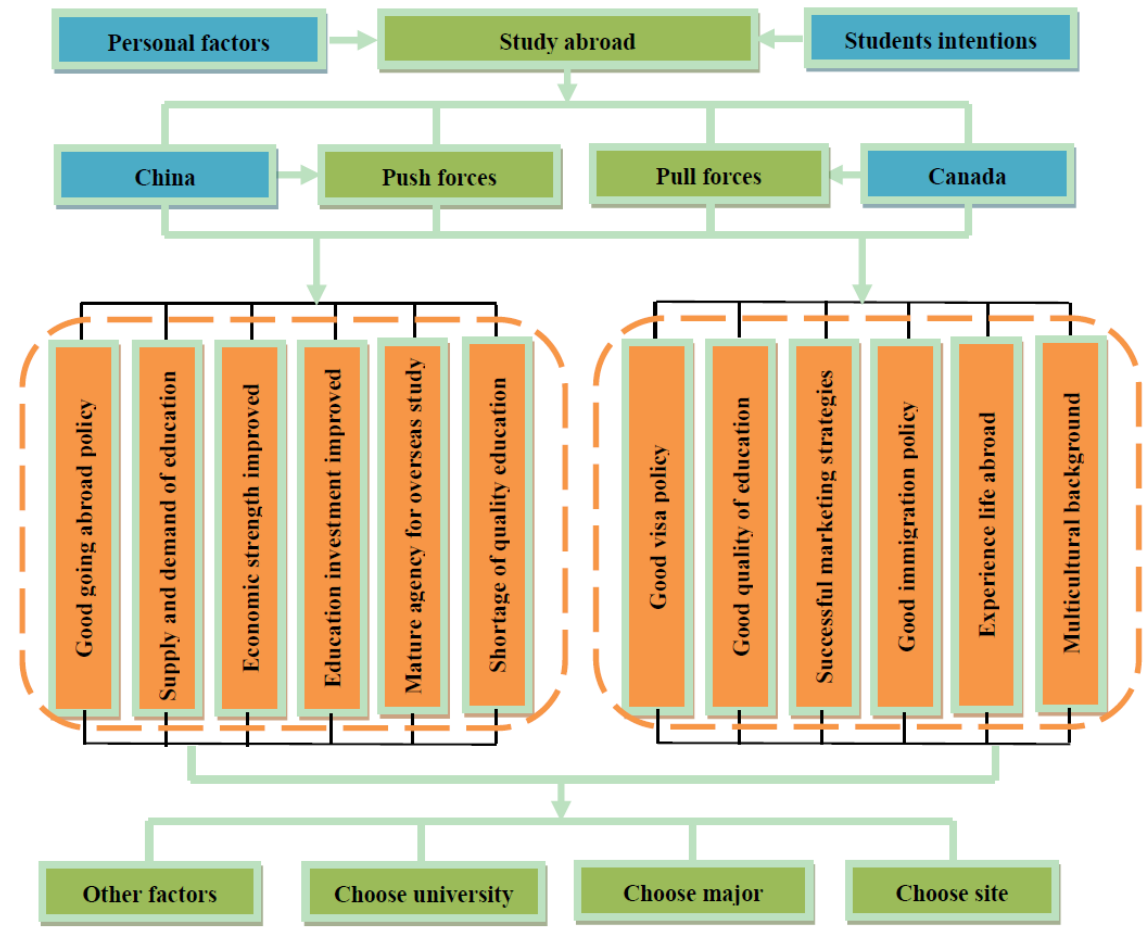

Figure 1 Theoretical model of impact of push-pull theory on Chinese high school students' Intentions to study in Canada

\subsection{Research Methods}

The subjects of this study are 95 students from a high school international class in an international school, 16 Chinese high school students who are going to study in Canada, and 16 Chinese high school students studying in a high school in Canada. The basic principle is random and voluntary. The research adopts a hybrid research method combining quantitative and qualitative methods [5]. Quantitative research is conducted through questionnaires to test the influence of "push-pull theory" factors on students' motivational status. The qualitative research was conducted through interviews, and interviewed with 16 Chinese students studying in high school going to Canada and 16 Chinese students studying in high school in Canada.

\section{RESULTS AND DISCUSSION}

\subsection{Questionnaire Analysis}

In this study, a hybrid research method combining quantitative and qualitative methods was used. The questionnaire used in the quantitative research is divided into two parts. The first part is personal information, including the gender, age and current grade of the participant; the second part is the "push-pull theory" factor survey. This part of the questionnaire has a total of 20 major questions, 66 sub-questions, mainly divided into four parts: personal situation and family background, students' willingness and demand to go abroad for higher education, influencing factors for students to choose to study abroad and main influencing factors for making various choices to study abroad. Among them, the influencing factors can be divided into three types of push and pull factors, such as the advantages and disadvantages of Chinese and overseas higher education, as well as the value judgments of students for higher education abroad and whether they have subjective motives for studying abroad. For the influencing factors of students' choice to 
study abroad, 46 questions in this part are scored by Likert's five-point scoring method. Qualitative research was completed through online interviews, the whole process went smoothly, and it was used as an important source of research information after collation and analysis. The author interviewed 32 subjects separately. For the interview, the author designed two types of questions. One category is for students who plan to study in Canada, a total of 10 interview questions; the other category is for students who are studying in Canada, a total of 10 interview questions. Before starting to answer the interview questions, the author first asked the subjects some general questions. For example, instead of directly asking the interviewee's views on the "push-pull theory factor", they asked the interviewee "Your parents support you to go abroad Study abroad", "Do you have any family, friends or classmates studying, working and living overseas?" Through similar questions, the author can get a more comprehensive understanding and avoid making "push-pull theory" a constraint. There is no limit to the answers of the subjects. The interview time for each subject is about 8 minutes.

\subsection{Reliability Analysis of Questionnaire}

Cronbach's alpha is a method of examining reliability. Cronbach's alpha is the most commonly used reliability assessment tool in psychological or educational tests. The Kronbach coefficient formula[5] is shown in formula (1) :

$\alpha=(n / n-1)\left(1-\sum S i 2 / S t 2\right)$

Among them, $\alpha$ is the reliability coefficient, $\mathrm{n}$ is the number of test questions, Si2 represents the variance of the score of all subjects on the $\mathrm{i}$-th question, and $\mathrm{St} 2$ is the variance of the total score of all the subjects. The $\alpha$ coefficient is the average of all possible split-half reliability. It is only an estimate of the lower bound of the test reliability. That is, if the $\alpha$ value is large, there must be a high reliability, but if the $\alpha$ value is small, it cannot be determined that the reliability is not high. In general, the higher the coefficient, the higher the reliability of the tool. In basic research, the reliability should be at least 0.80 to be acceptable. In exploratory research, the reliability is acceptable as long as it reaches 0.70 , between 0.70 and 0.98 are high reliability, and below 0.35 is low reliability Must be rejected. The questionnaires in this study were collected and filled out in 10 minutes between students. 95 questionnaires were distributed and 90 were effectively recovered. The data obtained was analyzed using SPSS statistical analysis software. For this part of the questions, the internal consistency coefficient (a coefficient) has been calculated by SPSS to test the reliability. After calculation, the internal consistency coefficient between these 46 questions is 0.926 , which is between 0.70 and 0.98 . Therefore, the reliability of this questionnaire is relatively high; at the same time, the structural validity is checked by factor analysis. After calculation, the total variance explained by this part of the questions has reached $76.8 \%$, which can basically reach the measurement target. This shows that the total questionnaire designed in this study has high reliability.

\subsection{Analysis of Driving Force on Studying Abroad}

There are many factors influencing Chinese high school students to study abroad in Canada. In this study, a theoretical model is established based on relevant data, and research and analysis are conducted based on 6 main factors, and there are 6 aspects of the research results[1,2,5]. (1) Loose study abroad policy[2]. The Chinese government resolutely implements the guidelines of "supporting study abroad, encouraging return to the country, and coming and going freely", creating a relaxed environment for studying abroad to encourage selffinanced study abroad. (2) The imbalance between supply and demand in higher education[1,5]. There are two different types of demand in the domestic higher education market-excess demand and differential demand. The former refers to the shortage of domestic university admission opportunities, and consumers turn to foreign countries to seek higher education resources; the latter refers to the outflow of students due to the inability to satisfy the quality or category of domestic higher education services. (3) Insufficient high-quality educational institutions[5]. Although the acceptance rate of the college entrance examination is currently high, due to the lack of high-quality resources, the proportion of students who can be admitted by famous schools such as "985" and "211" is still very low. Once an individual finds that the external market provides higher education services that meet the demand, it will produce Motivations that flow abroad. (4) Comprehensive economic strength improved[1,5]. From an economic perspective, the continued development of China's economy and the substantial increase in per capita payable income constitute a strong impetus for self-financed study abroad. (5) The concept of family education investment is improved. Under the influence of the acceleration of the globalization of education, families in many cities have changed their philosophy of investment in children's higher education. Chinese parents are holding money to let their children go out. Eye-opening, long-sighted ideas to consume overseas higher education[5]. (6) Mature service industry for studying abroad[1,7]. The mature and convenient study abroad service industry makes the process of going abroad a simple and easy process, which plays a positive role in promoting people's decision to study abroad. 


\subsection{Analysis of Pull Force on Studying abroad}

The reason why Canada can quickly develop into the most popular destination for Chinese students is closely related to its study abroad policies, study environment, quality of higher education, and relations between the two countries[1,6,7]. (1) Loose visa policy[7]. The loose visa system implemented by the Canadian government has become a basic rally for attracting Chinese students. The Canadian government entered the Chinese study abroad market in a market-oriented manner, lowered the threshold for higher education consumption. (2) Good quality of education[1]. Canadian higher education resources are abundant. There are many world-famous universities with low entry thresholds and flexible admission conditions. This constitutes an effective supplementary supply for Chinese students who have been rigorously selected for high-quality higher education for a long time. (3) Successful marketing strategy[1]. In essence, international student mobility is both an education phenomenon and a trade phenomenon. The successful marketing strategy of Canadian international higher education in the Chinese market has driven the consumption of Chinese higher education abroad. (4) Inclined immigration policy[3]. Studying abroad is closely related to employment. Due to the economic benefits, employment experience and language improvement brought about by working abroad, foreign students usually consider the factors of whether they can work while studying. The Canadian federal government and most provinces have channels for permanent residents who apply to graduate students. These channels are unobstructed faster than other personnel applying for permanent residents, and the pass rate is high. (5) Close cooperation between the two countries[1,7]. Canadian and Chinese educational institutions cooperate very closely. (6) Multicultural background[1]. The unique geographical location and historical reasons have created the unique characteristics of the integration of Western and Eastern cultures in Canadian culture. The cultural background of Canada's combination of Chinese and Western cultures has formed a cultural attraction for Chinese students.

\section{CONCLUSION}

The research results show that different cultural experiences, new knowledge and skills, different education methods, and employment in Canada are the main "pull" factors for Chinese high school students to study abroad; China's loose policy of studying abroad, the imbalance between supply and demand in higher education, the lack of high-quality educational institutions and other aspects are the main "driving" factors for Chinese high school students to study abroad.

\section{ACKNOWLEDGMENT}

This work was supported by New Renaissance Academy Foundation of Canada (2019001), Kunming University of Science and Technology of Foundation (1302-619320190114).

\section{REFERENCES}

[1] Jun Mian Chen.Three Levels of Push-Pull Dynamics Among Chinese International Students' Decision to Study Abroad in the Canadian Context. Journal of International Students: Volume 7 Number 1 (2017), pp. 113-135.

[2] Ministry of Education Service Center. Retrieved from http://www.moe.edu.cn/jyb_xwfb/xw_fbh/moe_2069/xwf b h_2016n/xwfb.

[3] Citizenship \& Immigration Canada (CIC). (2020). Retrieved

from http://www.cic.gc.ca/english/resources/statistics/facts2013 -preliminary/08.asp.

[4] Philip G.Altbach.Comparative Higher Education:Knowledge,the University,and Development[M].Hong Kong:Comparative Education Research Center, the University of Hong Kong,1998.

[5] Genshu Lu, Mei Tian. Analysis of factors influencing college students' willingness to study abroad[J]. Fudan Education Forum, 2014,12(5):pp36-44.

[6] Top reasons to study in Canada.(2019). Retrieved from http://nracademy.ca/why-study-in-canada/.

[7] Canadian Federation of Students-Ontario. (2010). The Impact of Government Underfunding On Students. Retrieved from http://cfsontario.ca/ downloads/CFS Underfunding\%20Factsheet.pdf. 